zepine-induced severe cutaneous adverse drug reactions. J Eur Acad Dermatol Venereol 2013;27:356-364.

4. Yoon J, Oh CW, Kim CY. Stevens-johnson syndrome induced by vandetanib. Ann Dermatol 2011;23(Suppl 3):
S343-S345.

5. Lim YL, Thirumoorthy $T$. Serious cutaneous adverse reactions to traditional Chinese medicines. Singapore Med J 2005;46:714-717.

\title{
Schnitzler Syndrome: A Case Report and Review of Literature
}

\author{
Yoon Seob Kim, Yu Mee Song, Chul Hwan Bang, Hyun-Min Seo, Ji Hyun Lee, Young Min Park, \\ Jun Young Lee
}

Department of Dermatology, Seoul St. Mary's Hospital, College of Medicine, The Catholic University of Korea, Seoul, Korea

\section{Dear Editor:}

Schnitzler syndrome (SchS) is a rare autoinflammatory disease characterized by a recurrent urticaria and monoclonal gammopathy ${ }^{1}$. Herein, to our knowledge, we report the first case of SchS in Korea. The study protocol was approved by the Institutional Review Board of Seoul St. Mary's Hospital, The Catholic University of Korea (KC16ZISE0262).

A 64-year-old man presented with two year history of daily urticaria. On physical examination, wheals and erythematous patches were found on the trunk and both extremities (Fig. 1). In contrast to most patients with urticaria, there was no pruritus, and antihistamine therapies did not have any effect. Only systemic steroid treatment yielded transient symptom improvement. The individual lesions lasted about 24 hours and resolved completely.

Received December 12, 2016, Revised July 25, 2017, Accepted for publication August 16, 2017

Corresponding author: Jun Young Lee, Department of Dermatology, Seoul St. Mary's Hospital, College of Medicine, The Catholic University of Korea, 222 Banpo-daero, Seocho-gu, Seoul 06591, Korea. Tel: 82-2-2258-6222, Fax: 82-2-599-9950, E-mail: jylee@catholic.ac.kr ORCID: https://orcid.org/0000-0002-8650-1759

This is an Open Access article distributed under the terms of the Creative Commons Attribution Non-Commercial License (http://creativecommons. org/licenses/by-nc/4.0) which permits unrestricted non-commercial use, distribution, and reproduction in any medium, provided the original work is properly cited.

Copyright (c) The Korean Dermatological Association and The Korean Society for Investigative Dermatology
Associated symptoms were musculoskeletal pain, and bouts of fever. Laboratory investigations showed leukocytosis $\left(10.57 \times 10^{9} / \mathrm{L}\right)$, an elevated erythrocyte sedimentation rate $(77 \mathrm{~mm} / \mathrm{hr} ; 0 \sim 20 \mathrm{~mm} / \mathrm{hr})$ and an increased C-reactive protein (CRP) level (11.95 mg/L; $0.01 \sim 0.47 \mathrm{mg} / \mathrm{L})$. Increased immunoglobulin (Ig)M levels (852 mg/dL; 46 $260 \mathrm{mg} / \mathrm{dL}$ ), decreased IgG (831 mg/dL; 870 1,700 $\mathrm{mg} / \mathrm{dL}$ ) and $\operatorname{lgA}(99 \mathrm{mg} / \mathrm{dL} ; 110 \sim 410 \mathrm{mg} / \mathrm{dL}$ ) were detected. Elevated levels of free kappa light chain (32.95
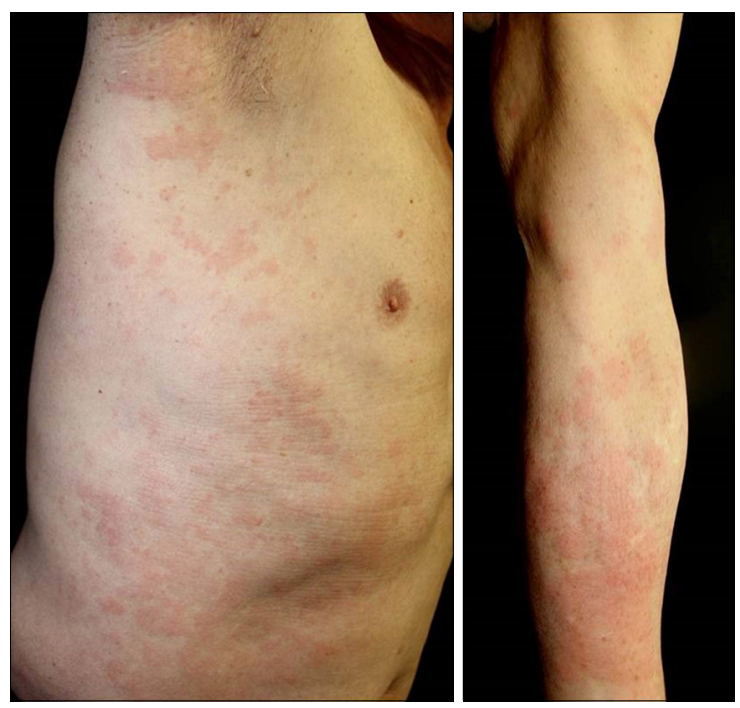

Fig. 1. On physical examination, wheals and erythematous patches were found on the trunk and both extremities. 

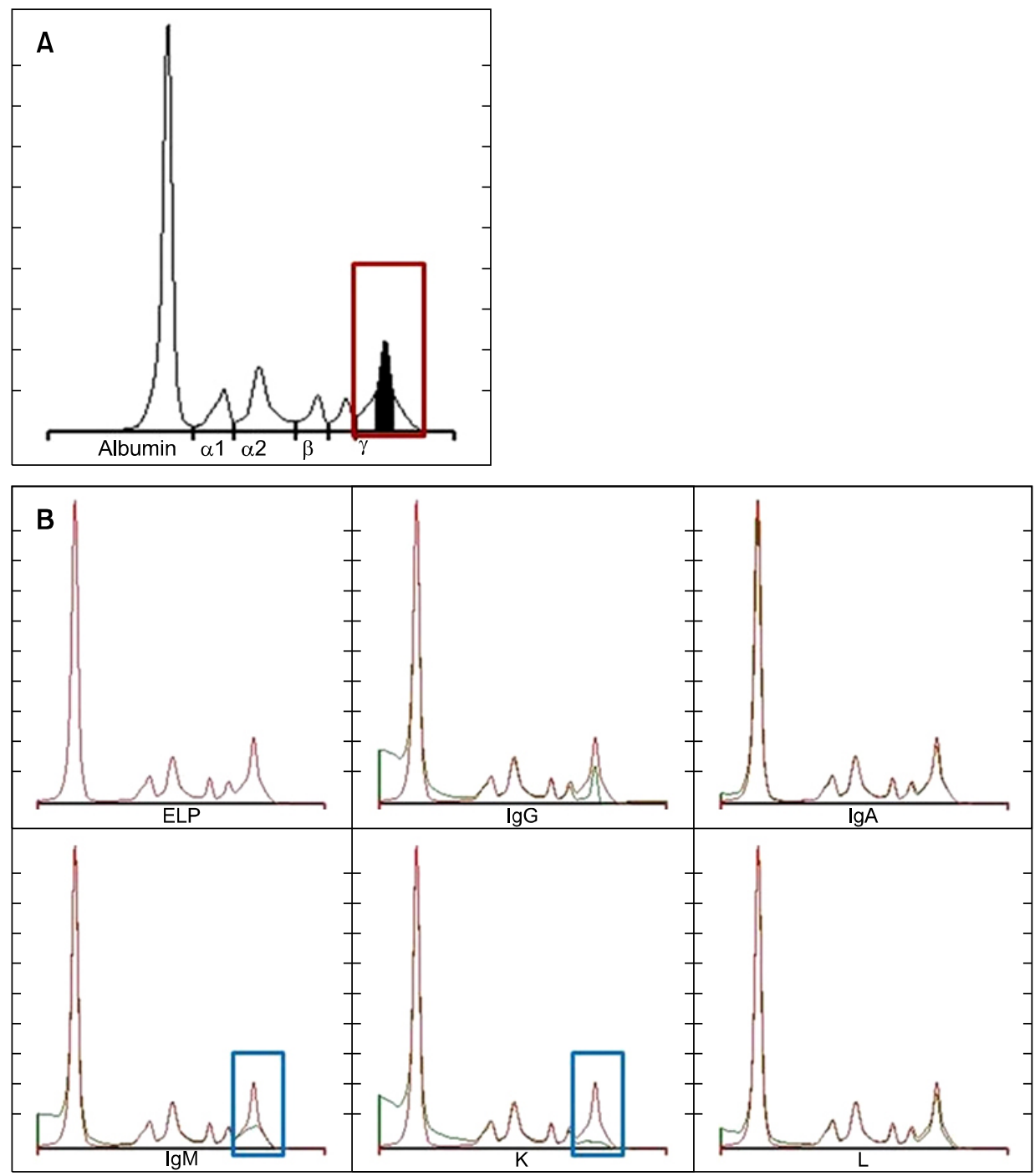

Fig. 2. (A) Serum protein electrophoresis and (B) immunofixation analysis showed the immunoglobulin (Ig)M ( $\kappa)$ monoclonal peak in the $\gamma$ fraction. ELP: electrophoresis, K: kappa light chain, L: lambda light chain.

$\mathrm{mg} / \mathrm{L} ; 3.30 \sim 19.40 \mathrm{mg} / \mathrm{L})$ were detected. Immunofixation analysis confirmed a monoclonal gammopathy of the IgM type (Fig. 2A, B). Based on these clinical and laboratory findings, he was diagnosed with SchS. Various steroid sparing agents such as cyclosporine, methotrexate, and dapsone were tried, and he showed relatively good effect to cyclosporine. We treated with cyclosporin 100 200 mg and antihistamines, and additionally systemic steroid and nonsteroidal anti-inflammatory drug for the acute exacerbation. He showed wax and waning course during the 5-year follow up periods.

According to the largest retrospective study of SchS, male/female ratio was 1.76 and the mean onset age was 51.6 years $^{1}$. IgM $(\kappa)$ light-chain gammopathy is predominantly reported in SchS (more than 90\%) ${ }^{2}$. Simon et al. ${ }^{1}$ proposed a set of Strasbourg diagnostic criteria that included two obligate criteria: (1) chronic urticarial rash and (2) monoclonal IgM or IgG, and four minor criteria: (1) re- current fever, (2) objective findings of abnormal bone remodeling with or without bone pain, (3) neutrophilic dermal infiltrate on skin biopsy, and (4) leukocytosis and/or elevated CRP. Definite diagnosis can be made for a patient who satisfies the two obligate criteria and at least two minor criteria if the patient has monoclonal IgM gammopathy, and at least three minor criteria if the patient has monoclonal IgG gammopathy. Therefore, our case was diagnosed as definite SchS. Possible exacerbating factors such as alcohol, spicy food, and psychological stress should be avoided, if identified ${ }^{3}$. Recommended treatment modalities include observation, colchicine, short-course nonsteroidal anti-inflammatory drugs and anakinra based on the degree of quality of life and inflammatory markers ${ }^{1}$. Long term follow-up is recommended due to risk of a lymphoproliferative disorders ${ }^{4}$.

Although cases of SchS have been reported worldwide, there was no report of SchS in Korea. One retrospective 
study reviewed 609 patients with recurrent urticaria who received laboratory investigations of CRP and protein electrophoresis, and found that none fulfilled criteria for $\mathrm{SchS}^{5}$. We speculated that genetic factors and unrecognized cases might contribute to the low incidence in Korea. Physicians should suspect SchS in cases of recurrent urticaria with atypical clinical features.

\section{CONFLICT OF INTEREST}

The authors have nothing to disclose.

\section{REFERENCES}

1. Simon A, Asli B, Braun-Falco $M$, De Koning $H$, Fermand JP, Grattan C, et al. Schnitzler's syndrome: diagnosis, treatment, and follow-up. Allergy 2013;68:562-568.
2. Sokumbi O, Drage LA, Peters MS. Clinical and histopathologic review of Schnitzler syndrome: the Mayo Clinic experience (1972-2011). J Am Acad Dermatol 2012;67: 1289-1295.

3. de Koning HD, Bodar EJ, van der Meer JW, Simon A; Schnitzler Syndrome Study Group. Schnitzler syndrome: beyond the case reports: review and follow-up of 94 patients with an emphasis on prognosis and treatment. Semin Arthritis Rheum 2007;37:137-148.

4. Gameiro A, Gouveia M, Pereira M, Tellechea O, Gonçalo M. Clinical characterization and long-term follow-up of Schnitzler syndrome. Clin Exp Dermatol 2016;41:461-467.

5. Shin JJ, Lee JM, Jang HW, Jung SK, Kim IH. Chronic urticaria and monoclonal gammopathy: does Schnitzler syndrome exist in Koreans? Proceedings of the 66th Annual Conference of Korean Dermatological Association, 2014 Oct 18-19; Seoul, Korea. p. 280.

\title{
Differential Effects of Digoxin on Imiquimod-Induced Psoriasis-Like Skin Inflammation on the Ear and Back
}

\author{
Marie Madsen ${ }^{1}$, Tanja Xenia Pedersen ${ }^{1}$, Lars Bo Nielsen ${ }^{1,2}$, Claus Johansen ${ }^{3}$, Peter Riis Hansen ${ }^{1,4}$ \\ ${ }^{1}$ Department of Biomedical Sciences, University of Copenhagen, ${ }^{2}$ Department of Clinical Biochemistry, Rigshospitalet, Copenhagen \\ University Hospital, Copenhagen, ${ }^{3}$ Department of Dermatology, Aarhus University Hospital, Aarhus, ${ }^{4}$ Department of Cardiology, \\ Herlev-Gentofte University Hospital, Hellerup, Denmark
}

Dear Editor:

Psoriasis is a chronic inflammatory skin disease in which interleukin (IL)-17-producing T helper (Th) 17 cells play a crucial role ${ }^{1}$. Topical application of the toll-like receptor 7 agonist imiquimod (IMQ) on the ear and/or back skin of mice is a widely used IL-17-dependent model of psoriasis-like skin inflammation ${ }^{2}$. The transcription factor reti- noid acid-related orphan receptor $\gamma \mathrm{t}(\operatorname{ROR} \gamma \mathrm{t})$ is required for IL-17 production by Th17 cells ${ }^{3}$. IMQ-induced skin inflammation is reduced both in ROR $\gamma \mathrm{t}$-deficient mice and upon pharmacological inhibition of $\operatorname{ROR} \gamma \mathrm{t}$ activity with novel small molecule selective $\operatorname{ROR} \gamma$ t inhibitors, indicating that $\operatorname{ROR} \gamma \mathrm{t}$ is crucial for IMQ-induced psoriasis-like skin inflammation in mice and suggesting a potential role

Received February 28, 2017, Revised July 22, 2017, Accepted for publication August 16, 2017

Corresponding author: Marie Madsen, Department of Biomedical Sciences, University of Copenhagen, Blegdamsvej 3B, DK-2200 Copenhagen, Denmark. Tel: 45-30-29-36-10, Fax: 45-35-32-75-55, E-mail: mariemad@sund.ku.dk ORCID: https://orcid.org/0000-0001-6579-9376

This is an Open Access article distributed under the terms of the Creative Commons Attribution Non-Commercial License (http://creativecommons.org/ licenses/by-nc/4.0) which permits unrestricted non-commercial use, distribution, and reproduction in any medium, provided the original work is properly cited.

Copyright (C) The Korean Dermatological Association and The Korean Society for Investigative Dermatology 